\title{
Current status of calcitonin gene-related peptide-based therapies in migraine: a scoping review
}

\author{
Marya Ahsan ${ }^{1 *}$, Ayaz Khurram Mallick ${ }^{2}$
}

\author{
${ }^{1}$ Department of Pharmacology, College of Medicine, Imam Mohammad Ibn Saud Islamic University, Riyadh, Saudi \\ Arabia \\ ${ }^{2}$ Department of Clinical Biochemistry, College of Medicine, King Khalid University, Abha, Saudi Arabia
}

Received: 26 December 2021

Accepted: 12 January 2022

\section{*Correspondence:}

Dr. Marya Ahsan,

Email: marya.ahsan@gmail.com

Copyright: (C) the author(s), publisher and licensee Medip Academy. This is an open-access article distributed under the terms of the Creative Commons Attribution Non-Commercial License, which permits unrestricted non-commercial use, distribution, and reproduction in any medium, provided the original work is properly cited.

\begin{abstract}
A significant proportion of patients exhibit sub-optimal response to the standard treatment of acute migraine such as triptans and NSAIDs. Even the conventional preventive therapies (e.g. beta-blockers) indicated for patients with frequent migraine attacks have varying responses. Moreover, evidence from animal studies elucidated the role of calcitonin gene-related peptide (CGRP) in the pathophysiology of migraine. Currently two classes are drug, the small molecule CGRP receptor antagonist or the 'gepants' (Ubrogepant, Rimegepant, Atogepant, Zavegepant) and CGRP monoclonal antibodies (Erenumab, Galcanezumab, Fremanezumab, Eptinezumab) have been found efficacious and safe in various clinical trials for the treatment and prevention of migraine. While the small molecule CGRP receptor antagonists are given orally, the monoclonal antibodies are injectable drugs. Ubrogepant and Rimegepant are the second-generation gepants approved for treatment of migraine. Zavegepant is a third generation gepant which has proven efficacy for acute treatment of migraine in a phase III trial. Atogepant has been approved for prevention of migraine. Rimegepant has also proven to be efficacious for preventing migraine attacks but has not yet been approved for this indication. Erenumab is the only monoclonal antibody which neutralizes the CGRP receptor. The latter three monoclonal antibodies target the CGRP peptide. The monoclonal antibodies have been approved for the prevention of migraine as a subcutaneously or intravenous infusion (Eptinezumab) given once a month or quarterly. Both the classes of drugs were well-tolerated in the clinical trials. Nausea was the most common adverse effect with gepants while injection-site pain was commonly reported with the antibodies.
\end{abstract}

Keywords: Episodic migraine, Calcitonin gene-related peptide, CGRP receptor antagonists, CGRP monoclonal antibodies

\section{INTRODUCTION}

Migraine is characterized by recurrent, often debilitating, unilateral or bilateral, pulsatile headache, frequently associated with nausea, vomiting, photophobia or phonophobia. ${ }^{1,2}$ In $20-30 \%$ patients, migraine headaches can be preceded by aura which can manifest as visual, auditory, olfactory or somatosensory symptoms. ${ }^{3}$ Based upon the frequency of migraine attacks in a month, patients are classified as suffering from episodic migraine $(<15$ days per month for three months) or chronic migraine $(\geq 15$ days per month with at least 8 days of headache with migraine features for more than three months). ${ }^{2}$ In addition to marked functional impairment, it has negative effects on physical, psychological, educational, occupational and social aspects of the patient's life. ${ }^{4}$ Though migraine does not cause premature death, it is nevertheless responsible for significant loss of years of healthy life, especially in young adults. ${ }^{5}$

Despite the wide availability of effective anti-migraine treatments such as triptans and ergot alkaloids, patients exhibit varying treatment response. A significant 
proportion of patients are refractory to conventional abortive treatments. ${ }^{6,7}$ Suboptimal efficacy of abortive treatment not only increases the duration of pain during an attack or leads to relapse after initial relief, but also increases the risk of chronification of migraine and development of medication-overuse headache ${ }^{8-10}$ Both the conditions are more difficult to manage. ${ }^{11,12}$ Patients with more than four migraine attacks per month or migraine attacks interfering adversely with daily life are offered preventive therapies. ${ }^{13}$ However, the conventional preventive therapies, which can include beta-blockers, calcium-channel blockers, anti-convulsant or antidepressants, have varying success rates in different individuals. ${ }^{14}$ The lack of efficacy and presence of adverse effects required revisiting of pre-clinical studies and the search for novel targets and drugs for the management of migraine.

Since the early 1990s, there was evidence from animal studies regarding the role of Calcitonin gene-related peptide (CGRP) in the pathophysiology of migraine. ${ }^{15}$ CGRP belongs to a family of peptides which includes Calcitonin (CT), adrenomedullin and amylin. It exists in two isoforms: $\alpha$-CGRP and $\beta$-CGRP. While $\alpha$-CGRP is predominantly expressed in the sensory neurons, $\beta$-CGRP is present in the enteric nervous system. CGRP binds to a class B G-protein coupled receptor (GPCR) which consists of a complex of a CT receptor-like receptor (CLR) domain and the receptor activity modifying protein 1 (RAMP 1). The C-terminal of CGRP binds to the extracellular $\mathrm{N}$ terminal regions of CLR and RAMP-1, inducing an affinity trap which further increases the local concentrations of CGRP. ${ }^{16}$

The CGRP receptors and sensory fibres containing CGRP are distributed both centrally and peripherally. It was recognized from immunohistochemical studies that CGRP, is released in the trigeminovascular complex and is responsible for causing neurogenic inflammation and vasodilation. ${ }^{17-19}$ Pharmacological experiments with sumatriptan (5-HT-1D agonist/triptan) hypothesize that since triptans normalize CGRP levels in migraine by inhibiting its release in the meninges, this mechanism contributes to its therapeutic efficacy. ${ }^{20}$ This was supported by findings of a significant study which demonstrated that intravenous infusion of CGRP triggered migraine headache in patients with a history of migraine. ${ }^{21}$ From these findings, it was postulated that if CGRP could induce an attack of migraine, antagonizing CGRP can treat migraine.

Recent developments in drug delivery and successful completion of phase III clinical trials in the last few years demonstrating efficacy and safety of drugs targeting the CGRP or its receptor have created keen interest among the pharmaceutical industry for these landmark anti-migraine drugs. ${ }^{15}$ Many of these drugs have recently been approved by the FDA for abortive and preventive therapy in migraine. ${ }^{22-28}$ Of these therapies, the small molecule CGRP receptor antagonists (CGRP-RAs) are also called the 'gepants'. While rimegepant and ubrogepant have proven to be efficacious in the acute management of migraine, atogepant has shown efficacy in prevention of migraine attacks. ${ }^{22-24}$ In addition to gepants, biologic therapies targeting the CGRP or its receptors (CGRP-mAb) have also been developed. Of these three (Eptinezumab, Fremanezumab And Galcanezumab), Monoclonal antibodies (mAb) target CGRP while only one monoclonal antibody (Erenumab) binds to CGRP receptor. These mAbs have been approved for the prevention of acute attacks in patients of migraine. ${ }^{25-28}$ While the monoclonal antibodies are injectable drugs, administered subcutaneously or intravenously once a month or every three months, the gepants are oral drugs most of which can be taken as and when required.

This scoping review was conducted in order to identify key concepts, existing knowledge gaps and map the research in the field of CGRP-based therapies for adult migraineurs. All CGRP-based drugs (CGRP-RAs and CGRP-mAb) have been described. New therapies, other than those based on CGRP were beyond the scope of this review. As there are yet no studies of impact comparing this new class of drugs with conventional standard therapy (triptans), we could not conduct a systematic review to compare them. Hence, with this scoping review we aim to give an overview of the efficacy and safety profile of calcitonin gene-related peptide modulators in the treatment and prevention of episodic migraine in the adult population.

\section{DATA COLLECTION}

The MEDLINE, EMBASE, Web of Science, and EBSCOhost databases were searched systematically for indexed, peer-reviewed published literature in the English language between January 2012 to November 2021. The NIH U.S. National Library of Medicine ClinicalTrials.gov was also searched for relevant studies. The search was conducted using the Boolean phrase with keywords ('Migraine' or 'Migraineur') and ('Calcitonin Gene Related Peptide' or 'CGRP receptor antagonists' or 'Gepants' or 'Ubrogepant' or 'Rimegepant' or 'Atogepant' or 'CGRP monoclonal antibodies' or 'Eptinezumab' or 'Fremanezumab' or 'Galcanezumab' or 'Erenumab'). The search results were exported into ENDnote X6 and duplicates were removed. Initial eligibility screening was performed by assessing the titles and abstracts (level 1). The full-text copies of the eligible articles were further reviewed by two authors (level 2). If full texts could not be retrieved the articles were excluded. The Population, intervention, comparator, outcome (PICO) strategy was largely used for defining inclusion and exclusion criteria for this review (Table 1). Studies were included in this scoping review if they met the following criteria: Double-blinded randomized placebocontrolled Phase II and III clinical trials evaluating the role of CGRP-based therapies (CGRP-RAs and CGRP-mAb) in adult patients of both genders diagnosed with episodic migraine according to International Classification of Headache Disorder III (ICHD-III). ${ }^{2}$ Though review articles 
were not included in the scoping review, they were scanned to identify any missing study.

\section{SMALL MOLECULE CGRP RECEPTOR ANTAGONISTS (CGRP-RA)}

This class of drugs blocks the CGRP-receptor and is also known as the 'gepants'. There have been two generations of gepants. The first generation, notably included intravenous Olcegepant and oral telecagepant. ${ }^{29-31}$ Though these drugs proved efficacious and safe for acute treatment, their development of first generation gepants was stopped because of hepatotoxicity observed in patients put on gepants for preventive therapy. ${ }^{29}$ Following this, four second generation gepants have been developed, three of which have been approved by the FDA. ${ }^{22,24}$ The second generation drugs include Rimegepant, Ubrogepant, Atogepant and Zavegepant. ${ }^{29,32-41}$ Rimegepant and Ubrogepant are oral drugs approved for acute treatment of migraine while atogepant is an approved oral preventive therapy. Oral Rimegepant is also being investigated in clinical trials as preventive therapy, but has not yet been approved for this indication. ${ }^{42}$ Zavegepant is being developed as a nasal preparation for acute treatment of migraine, awaiting approval (Table 2 and 3). ${ }^{39}$ The greatest advantage of CGRP-RA is that unlike the triptans, it can be used in patients with vascular disease. ${ }^{29}$

\section{UBROGEPANT}

Following the risk of hepatotoxicity with first generation gepants, structural changes were made in the molecule to address the risk of hepatotoxicity. This led to the development of a novel small molecule CGRP-RA, Ubrogepant (MK-1602). ${ }^{29}$ Ubrogepant (UBRELVY ${ }^{\mathrm{TM}}$ ) was approved by the US-FDA in December 2019 for acute treatment of migraine. ${ }^{22}$ It completed a Phase II dosefinding study (NCT01613248) which compared $1 \mathrm{mg}, 10$ $\mathrm{mg}, 25 \mathrm{mg}, 50 \mathrm{mg}$ and $100 \mathrm{mg}$ oral dose of Ubrogepant with placebo which was published in $2016 .{ }^{32}$ Voss et al enrolled 834 patients with 2-8 moderate to severe migraine attacks per month in this double-blinded Randomized controlled trial (RCT). They reported Ubrogepant superior to placebo at the $25 \mathrm{mg}, 50 \mathrm{mg}$ and $100 \mathrm{mg}$ doses in terms of percentage of patients headache-free at the 2 hour interval. Though they found Ubrogepant to be superior to placebo in relieving photophobia and phonophobia at 2 hours post-dosing, they did not specify the Mostbothersome symptom (MBS). ${ }^{32}$ This phase II trial was followed by the ACHIEVE-1 (NCT02828020) and ACHIEVE-2 (NCT02867709) phase III trials doubleblinded randomized placebo-controlled trials, the results of which led to approval by the FDA. ${ }^{33,34}$ The ACHIEVE1 trial, enrolled 1672 patients and compared single dose of oral ubrogepant $50 \mathrm{mg}$ and $100 \mathrm{mg}$ with placebo. Both the $50 \mathrm{mg}$ and $100 \mathrm{mg}$ doses were found to be superior to placebo in attaining the primary efficacy end-point of headache-freedom at 2 hours post-dosing $(50 \mathrm{mg}=19.2 \%$, $\mathrm{OR}=1.83,95 \% \mathrm{CI}=1.25$ to $2.66, \mathrm{p}<0.01 ; 100 \mathrm{mg}=21.2 \%$, $\mathrm{OR}=2.04, \quad 95 \% \mathrm{CI}=1.41$ to $2.95, \mathrm{p}<0.001)$, with $\mathrm{a}$ therapeutic gain of $7.4 \%$ with $50 \mathrm{mg}$ dose and $9.4 \%$ with the $100 \mathrm{mg}$ dose. ${ }^{33} \mathrm{In}$ ACHIEVE-2 trial, the $25 \mathrm{mg}$ and 50 $\mathrm{mg}$ Ubrogepant doses were compared with placebo in a modified intention to treat analysis analysis. The $50 \mathrm{mg}$ dose was again found to have significant efficacy in achieving pain-freedom at 2 hours post dose. ${ }^{34}$ Ubrogepant was also superior to placebo in both in trials in achieving MBS-freedom at 2 hours post-dose. Ubrogepant was well tolerated in both the phase III RCTs (ACHIEVE 1 and 2). No serious adverse effects were reported with Ubrogepant use. The most commonly reported adverse events were nausea, dry mouth, dizziness and somnolence. Though four cases of ALT elevation were reported in these trials, they were later found to be unrelated to ubrogepant use (Table 2). ${ }^{33,34}$

\section{RIMEGEPANT}

Rimegepant, orally disintegrating tablet (Nurtec ODT), was approved by the US-FDA in February 2020 for the acute treatment of episodic migraine. ${ }^{23}$ Marcus et al conducted the first phase II dose-ranging study (NCT01430442) in which 502 patients were randomized to receive different doses of oral rimegepant (BMS927711) ranging from $10 \mathrm{mg}$ to $600 \mathrm{mg}$ OD. ${ }^{35}$ Doses of 75 $\mathrm{mg}, 150 \mathrm{mg}, 300 \mathrm{mg}$ and $600 \mathrm{mg}$ showed greater efficacy in treating a single attack of migraine in comparison to placebo. Further phase III studies also evaluated Rimegepant $75 \mathrm{mg}$ in double-blinded placebo-controlled trials. ${ }^{36-38}$ Two of these phase III trials (NCT03237845, NCT03461757) have been published while another one (Study BHV3000-301, NCT03235479) has not been published yet. All these studies had a similar design and participants were enrolled if they had less than 15 days with headache in a month and not more than eight attacks of moderate to severe migraine in a month over a period of last three months. The patients were randomized to receive oral Rimegepant $75 \mathrm{mg}$ OD or matched placebo. All the phase III trials found Rimegepant to be superior in comparison to a placebo in terms of percentage of patients headache-free at 2 hours post-dosing. Lipton et al completed the trial in 1080 patients, reported that $19.6 \%$ patients were headache free at 2 hours in the Rimegepant group compared to $12 \%$ in the placebo group (Risk difference, $\mathrm{RD}=7.6,95 \% \mathrm{CI} 3.3-11.9, \mathrm{p}<0.001)$, yielding a Therapeutic gain (TG) of $7.6 \% .{ }^{36}$ Study data by Croop et al from 1368 patients, found that $21.2 \%$ and $10.9 \%$ patients were headache free in Rimegepant ODT and placebo groups respectively $(\mathrm{RD}=10.4,95 \% \mathrm{CI}=6.5-14.2$, $\mathrm{p}<0.001$, with a TG of $10.3 \% .{ }^{37}$ Similar results were reported by study $301 .{ }^{38}$ Migraine is commonly associated with photophobia, phonophobia and nausea. However, the intensity of the symptoms varies in each individual. Absence of Most-bothersome symptom (MBS) at 2 hours post-dosing was also considered as a primary end-point in all the studies. Phase III trials reported $35-37.6 \%$ patients MBS-free at 2 hours after Rimegepant in comparison to $25-27 \%$ patients in the placebo group $(\mathrm{p}<0.001) .{ }^{36-38}$ On assessing the safety profile of in acute treatment of episodic migraine, no serious adverse events were 
attributed to Rimegepant. Rimegepant was well-tolerated with only mild adverse events like nausea, vomiting, dizziness and Urinary tract infection (UTI). ${ }^{35-38}$ Hepatotoxicity was not reported with Rimegepant in any of the studies, unlike its predecessors. Following the success of Rimegepant as an abortive treatment, it has also been tried for prevention of migraine in patients reporting 4-18 attacks of moderate migraine in a double-blinded randomized placebo-controlled phase IIb/III study conducted by Croop et al. ${ }^{42} 1591$ patients enrolled in the trial received single dose of $75 \mathrm{mg}$ oral Rimegepant every other day for 12 weeks or matched placebo. The primary efficacy endpoint of the study was change from the in the mean number of migraine days per month in the last 4 weeks (weeks 9-12) in comparison to the observation period. Rimegepant was superior to placebo in preventing migraine. The change in the mean number of migraine days was -4.3 days $(95 \%=\mathrm{CI}=-4.8$ to -3.9$)$ with Rimegepant and -3.5 days $(95 \% \mathrm{CI}=-4.0$ to -3.0$)$ with placebo (least squares mean difference- 0.8 days, $95 \% \mathrm{CI}=-$ 1.46 to $-0.20, \mathrm{p}<0.01)$. On comparing the secondary efficacy end-point of at least $50 \%$ reduction in mean number of moderate to severe migraine episodes, Rimegepant was found to be superior to placebo. ${ }^{42}$ These findings have placed Rimegepant in the unique position of being the only drug to be efficacious as acute and preventive treatment of migraine (Table 2 and 3 ).

\section{ATOGEPANT}

Atogepant (Quilipta ${ }^{\mathrm{TM}}$ ) is the most recently approved oral small molecule CGRP-RA approved as preventive therapy in patients of episodic migraine by the US-FDA in September $2021 .^{24}$ Goadsby et al enrolled 834 patients in a double-blinded randomized placebo-controlled trial (NCT02848326) evaluating different doses of atogepant given once or twice daily in five groups $(10 \mathrm{mg} \mathrm{OD}, 30 \mathrm{mg}$ OD, $60 \mathrm{mg}$ OD, $30 \mathrm{mg}$ BID or $60 \mathrm{mg}$ BID) as preventive therapy for episodic migraine. ${ }^{40}$ The ADVANCE trial (NCT03777059) conducted by Ailani et al enrolled 910 patients, of which 659 were assigned to different doses of atogepant. ${ }^{41}$ There was a decrease in the mean number of migraine days in patients prescribed $10 \mathrm{mg}, 30 \mathrm{mg}$ or 60 $\mathrm{mg}$ Atogepant daily for a period of 12 weeks in comparison to placebo in a dose-dependent manner. 55$60 \%$ patients in the Atogepant group reported $50 \%$ or more reduction in migraine frequency over a period of three months in comparison to only $29 \%$ patients on placebo group. ${ }^{41}$ The most commonly reported adverse effect with Atogepant was constipation, though none of the adverse events were serious. ${ }^{41,42}$ Other reported adverse events included nausea and upper respiratory tract infection. Though studies have reported elevated Alanine transaminase (ALT) and Aspartate aminotransferases (AST), it is not clinically significant (Table 3). ${ }^{41,42}$

\section{ZAVEGEPANT}

Intra-nasal Zavegepant (BHV3500) has been tried in a dose-ranging phase II/III double-blinded placebo- controlled RCT (NCT03732638) for acute treatment of episodic migraine. ${ }^{39}$ Zavegepant is a third generation CGRP-RA. Zavegepant is structurally unique small molecule which binds selectively and with high affinity to the CGRP receptor. The molecular structure of zavegepant makes it suitable for subcutaneous, oral and topical administration (inhalation). Croop et al reported that the 1673 participants were randomized to treat a single attack of moderate to severe migraine with intranasal Zavegepant $5 \mathrm{mg}, 10 \mathrm{mg}, 20 \mathrm{mg}$ or matched placebo. The $10 \mathrm{mg}$ and $20 \mathrm{mg}$ dose were superior to placebo in achieving freedom from headache $(10 \mathrm{mg}$ : $22.5 \%, \mathrm{p}<0.05 ; 20 \mathrm{mg}$ : $23.1 \%$, $\mathrm{p}<0.01$, placebo=15.5\%). The intranasal route of administration of Zavegepant, makes it rapidly acting, with pain relief being reported as early as $15 \mathrm{~min}$. Sustained efficacy upto 48 hours following a single intranasal dose has also been reported. Zavegepant was also superior to placebo in achieving MBS-freedom [placebo: 33.7\%; $10 \mathrm{mg}$ : 41.9\%, p<0.05; $20 \mathrm{mg}: 42.5 \%$, $\mathrm{p}<0.01)$. Zavegepant has been reported to be safe as majority of the advere effect were mild to moderate in nature with dysgeusia and nasal discomfort being the most commonly reported adverse effects. Dysgeusia was reported in $13.5-16 \%$ patients on Zavegepant compared to $3.5 \%$ patients in the placebo group (Table 2). ${ }^{39}$

\section{CALCITONIN GENE-RELATED PEPTIDE MONOCLONAL ANTIBODIES (CGRP mAb)}

CGRP-mAbs are administered either subcutaneously or intravenously, and thus not suitable for frequent use as abortive therapy. The small molecule CGRP-RA are better suited as abortive therapy as they can be administered orally. ${ }^{29}$ However, the mAbs have long plasma half-lives, which makes infrequent dosing possible. ${ }^{16}$ These drugs have not shown any hepatotoxic potential in clinical studies as they lack toxic metabolites. These drugs are very specific and lack drug-drug interaction both due to specific action and lack of hepatic metabolism. Due to these advantages over CGRP-RA, they are used as preventive therapy for migraine. ${ }^{16}$ The CGRP-mAbs are large molecules $(150 \mathrm{kDa})$, which makes it difficult for them to cross the blood-brain barrier. As they have demonstrated efficacy in migraine, it highlights that their site of action is in the periphery, where they target CGRP and CGRP receptors. Their suggested sites of action in migraine are the trigeminal ganglion, periventricular structures and dura mater. Currently, there are four mAbs targeting CGRP or its receptor which have been approved by the FDA for prevention of migraine (Table 4). ${ }^{25-28}$ Erenumab is the only humanized $\mathrm{mAb}$ which neutralizes the CGRP receptor, while Fremanezumab, Galcanezumab And Eptinezumab neutralize the CGRP. All these drugs have been approved as preventive therapy for frequent migraine (more than four attacks per month) after being extensively studied in randomized clinical trials. ${ }^{43}$ Though, the different CGRP mAbs have diverse pharmaceutical characteristics, they are strikingly similar in their clinical efficacy profile. The CGRP mAbs exert their anti-migraine action through a peripheral action. The CGRP mAbs have been effective in 
decreasing the frequency of headaches in patients with frequent episodic migraine and chronic migraine. The proportion of patients who report at least $50 \%$ decrease in the frequency of moderate to severe migraine over a 3month period is significantly high with CGRP mAbs compared to placebo. Patients on CGRP mAbs report reduced consumption of abortive therapy after one month of use of CGRP mAbs. Some patients, designated as superresponders have reported more than $75 \%$ reduction in their migraine days, with some reporting complete resolution of migraine. Other than pain at the site of injection, these drugs are well-tolerated and have safety profiles similar to placebo.

\section{ERENUMAB}

Erenumab (AIMOVIG) is a fully human monoclonal antibody targeting the CGRP receptor. It prevents the binding of CGRP, a vasodilatory peptide to its receptor. It was approved by US-FDA in May 2018. ${ }^{25}$ Erenumab is given as once monthly subcutaneous injection and has been extensively studied in phase II and III trials (Table 4). ${ }^{43-45}$ A phase II RCT (NCT02630459) has evaluated the efficacy and safety of erenumab $28 \mathrm{mg}, 70 \mathrm{mg}$ and $140 \mathrm{mg}$ once a month for preventing migraine and found the $70 \mathrm{mg}$ dose superior to placebo in reducing the monthly migraine days $(-2.31, \quad 95 \% \mathrm{CI}:-3.00$ to $-1.62 ; \mathrm{p}<0.001){ }^{43}$ Nasopharyngitis was the most common adverse effect reported. ${ }^{43}$ In a phase III double-blinded placebocontrolled RCT, ARISE (NCT02483585), where $70 \mathrm{mg}$ Erenumab was found to be superior to placebo in reducing monthly migraine days and more than $50 \%$ reduction in migraine days per month was seen in $39.7 \%$ patients on erenumab. ${ }^{44}$ Another phase III randomized double-blinded RCT investigating Erenumab was the STRIVE trial (NCT02456740). ${ }^{45}$ The STRIVE trial enrolled 955 patients, who were randomized to receive Erenumab 70 $\mathrm{mg}, 150 \mathrm{mg}$ or matched placebo once a month. Erenumab is given in doses which is sufficient to prevent migraine. At these doses, Erenumab also blocks the CGRP receptor in the peripheral tissues, thus decreasing gastrointestinal motility and peristalsis which is mediated by CGRP. The use of this CGRP receptor blocking antibody thus predisposes some patients to gastrointestinal side effect constipation. ${ }^{43-45}$

\section{GALCANEZUMAB}

Galcanezumab (EMGALITY ${ }^{\mathrm{TM}}$ ) is a humanized $\mathrm{mAb}$ against the CGRP ligand. It was approved by the US-FDA in September 2018 as a once a month subcutaneous injection for prevention of migraine. ${ }^{26}$ In 2019 , it was also approved for the prevention of episodic cluster headaches. In a phase III double-blinded RCT (NCT02163993), 410 patients of episodic migraine were randomized to receive Galcanezumab $5 \mathrm{mg}, 50 \mathrm{mg}, 120 \mathrm{mg}$ or $300 \mathrm{mg}$ and matched placebo, once a month subcutaneously for 3 months. ${ }^{46}$ The $120 \mathrm{mg}$ dose of Galacenzumab significantly reduced the monthly migraine days compared to the placebo. Injection site pain, nasopharyngitis, dysmenorrhoea and nausea were the commonly reported TEAE (more than 5\% patients in Galcanezumab group). ${ }^{46}$ The EVOLVE-1 enrolled 858 patients in an intention to treat analysis and compared Galcanezumab $120 \mathrm{mg}$ and $240 \mathrm{mg}$ with placebo. Treatment with Galacanezumab significantly reduced the monthly migraine days by 4.7 and 4.6 days in the $120 \mathrm{mg}$ and $240 \mathrm{mg}$ group. ${ }^{47}$ The EVOLVE-2 trial (NCT02614196) also reported similar efficacy and safety results. ${ }^{48}$ The CONQUER trial (NCT03559257) enrolled patients who had treatment failure with at least two groups of preventive therapies. ${ }^{49}$ Patients were randomized to receive two doses of $120 \mathrm{mg}$ Galcanezumab as loading dose followed by $120 \mathrm{mg}$ dose per month for three months or matched placebo. Patients in the Galacanezumab group reported 4.1 fewer monthly migraine days during the treatment period while those on placebo reported only 1.0 fewer monthly migraine days. ${ }^{49}$ Treatment of Japanese patients of episodic migraine in a Phase II study (NCT02959177) with Galcanezumab 120 $\mathrm{mg}$ or $240 \mathrm{mg}$ was found to significantly improve the scores on the Migraine-specific quality of life questionnaire (MSQ) ${ }^{50}$ The improvement in score was seen withing one month in all the domains of the MSQ and it was sustained till 6 months (Table 4).

\section{FREMANEZUMAB}

Fremanezumab (AJOVY ${ }^{\mathrm{TM}}$ ) was approved by the FDA in September 2018. ${ }^{27}$ It was available as a pre-filled syringe (auto-injector) for one time use as preventive therapy of migraine. It is a fully humanized monoclonal antibody (Table 4). It has also been tried as preventive therapy of episodic cluster headache and post-traumatic headache disorder. In the phase III b FOCUS trial (NCT03308968), 271 patients of episodic or chronic migraine received Fremanezumab $675 \mathrm{mg}$ subcutaneously (three injection of $225 \mathrm{mg} / 1.5 \mathrm{ml}$ ) quarterly and 272 patients received the same dose monthly till day $140 .{ }^{51}$ The decrease in the monthly migraine days was significant in both the groups over a period of three months compared to the placebo. Those receiving quarterly dose reported a decrease of 3.7 days compared to 4.1 days decrease in those receiving monthly Fremanezumab. 34\% patients on Fremanezumab reported at least $50 \%$ reduction in monthly mean migraine days over three months. ${ }^{51}$ Though no difference was seen in the efficacy of quarterly and monthly doses, results from the HALO study (NCT02638103) showed that 69\% patients preferred quarterly fremanezumab. ${ }^{52,53}$ In addition to reaching the migraine related efficacy end-points, patients also reported improvement in quality of time spent with others, anxiety and sleep quality. ${ }^{53}$ The most commonly reported TEAEs were injection site reactions like induration, pain and erythema. ${ }^{51,52}$

\section{EPTINEZUMAB}

Eptinezumab (VYEPTI ${ }^{\mathrm{TM}}$ ) was approved by the US-FDA in February 2020 for the prevention of migraine in adults. ${ }^{28}$ Unlike other CGRP mAbs which are administered subcutaneously, Eptinezumab is given intravenously 
(Table 4). Eptinezumab is administerd as $100 \mathrm{mg}$ intravenous infusion every three months. It has demonstrated preventive efficacy from day 1 of its administration in phase III RCTs. The PROMISE-1 trial (NCT02559895) explored Eptinezumab for episodic migraine prevention while the PROMISE-2 trial was conducted in patients of chronic migraine. ${ }^{54}$ Upper respiratory infections, fatigue and nasopharyngitis were reported as treatment-emergent adverse events (TEAEs). Recently a phase III double-blinded RCT (RELIEF, NCT04152083) has investigated eptinezumab as abortive therapy for migraine. ${ }^{55}$ Though they have found intravenous infusion of $100 \mathrm{mg}$ Eptinezumab to meet the efficacy end-points, the feasibility of treatment needs to be further explored.

Table 1: Inclusion and exclusion criteria for eligible studies.

\begin{tabular}{|c|c|c|}
\hline Criterias & Inclusion & Exclusion \\
\hline Study & Phase II/phase III clinical trials & $\begin{array}{l}\text { Pre-clinical studies } \\
\text { Phase-I clinical trials }\end{array}$ \\
\hline Population & $\begin{array}{l}\text { Adults } \\
\text { Episodic migraine }\end{array}$ & $\begin{array}{l}\text { Animals/Migraine-disease models } \\
\text { Chronic migraine/tension headache/other } \\
\text { headache diagnoses }\end{array}$ \\
\hline Intervention & $\begin{array}{l}\text { CGRP-RA } \\
\text { CGRP-mAb }\end{array}$ & NSAIDs/Ergot alkaloids/Ditans \\
\hline Comparator & Placebo & No control group \\
\hline Outcome & $\begin{array}{l}\text { A. Acute treatment: } \\
\text { i. Percentage of patients headache } \\
\text { free at } 2 \text { hours } \\
\text { ii. Percentage of patients MBS-free } \\
\text { at } 2 \text { hours } \\
\text { B. Preventive treatment: } \\
\text { i. Change from baseline in mean } \\
\text { monthly migraine days } \\
\text { ii. Percentage of patients with at } \\
\text { least } 50 \% \text { reduction in mean } \\
\text { monthly days over three months }\end{array}$ & $\begin{array}{l}\text { Ill-defined outcome measures/ outcome } \\
\text { parameters not representative of migraine }\end{array}$ \\
\hline Publication & $\begin{array}{l}\text { English only } \\
\text { Between January } 2012 \text { to November } \\
2021\end{array}$ & $\begin{array}{l}\text { Language other than English } \\
\text { Before January } 2012 \\
\text { after November } 2021\end{array}$ \\
\hline
\end{tabular}

Table 2: Summary of Phase II/III clinical trials of CGRP-RA used for acute treatment of episodic migraine.

\begin{tabular}{|c|c|c|c|c|c|}
\hline Author/year & Study details & $\begin{array}{l}\text { Intervention } \\
(\mathbf{N})\end{array}$ & $\begin{array}{l}\text { Percentage of } \\
\text { patients pain } \\
\text { free at } 2 \mathrm{hrs}\end{array}$ & $\begin{array}{l}\text { Percentage of } \\
\text { patients MBS- } \\
\text { free at } 2 \text { hrs }\end{array}$ & $\begin{array}{l}\text { Commonly } \\
\text { reported TEAE }\end{array}$ \\
\hline \multicolumn{6}{|l|}{ Ubrogepant } \\
\hline \multirow{6}{*}{$\begin{array}{l}\text { Voss T et al, } \\
2016 .{ }^{32}\end{array}$} & \multirow{6}{*}{$\begin{array}{l}\text { Phase II } \\
\text { DB RCT } \\
\text { NCT01613248 }\end{array}$} & U 1 mg (107) & & $37.4 *$ & \multirow{6}{*}{$\begin{array}{l}\text { Dizziness } \\
\text { Somnolence } \\
\text { Dry mouth }\end{array}$} \\
\hline & & U 10 mg (108) & 20.7 & 34.1 & \\
\hline & & U $25 \mathrm{mg}(103)$ & 21.4 & $39.8 *$ & \\
\hline & & U $50 \mathrm{mg}(105)$ & 21.0 & $47.6^{*}$ & \\
\hline & & $\begin{array}{l}\mathrm{U} 100 \mathrm{mg} \\
(102)\end{array}$ & 25.5 & $54.9 *$ & \\
\hline & & Placebo (112) & 8.9 & $30.4 *$ & \\
\hline \multirow{3}{*}{$\begin{array}{l}\text { Dodick et al, } \\
2019 .{ }^{33}\end{array}$} & Phase III & U $50 \mathrm{mg}(422)$ & 19.2 & 38.6 & \multirow{3}{*}{$\begin{array}{l}\text { Nausea } \\
\text { Somnolence } \\
\text { Dry mouth }\end{array}$} \\
\hline & $\begin{array}{l}\text { DB RCT } \\
\text { ACHIEVE-1 }\end{array}$ & $\begin{array}{l}\mathrm{U} 100 \mathrm{mg} \\
(448)\end{array}$ & 21.2 & 37.7 & \\
\hline & NCT02828020 & Placebo (456) & 11.8 & 27.8 & \\
\hline \multirow{3}{*}{$\begin{array}{l}\text { Lipton et al, } \\
2019 .{ }^{34}\end{array}$} & Phase III & U $25 \mathrm{mg}(435)$ & & & \multirow{3}{*}{$\begin{array}{l}\text { Nausea } \\
\text { Dizziness }\end{array}$} \\
\hline & DB RCT & U $50 \mathrm{mg}(464)$ & 21.8 & 38.9 & \\
\hline & $\begin{array}{l}\text { ACHIEVE-2 } \\
\text { NCT02867709 }\end{array}$ & Placebo (456) & 14.3 & 27.4 & \\
\hline \multicolumn{6}{|l|}{ Rimegepant } \\
\hline \multirow{3}{*}{$\begin{array}{l}\text { Marcus et al, } \\
2014 .{ }^{35}\end{array}$} & Phase II & R 10 mg (71) & 19.7 & 18.3 & \multirow{3}{*}{$\begin{array}{l}\text { Nausea } \\
\text { Dizziness } \\
\text { Vomiting }\end{array}$} \\
\hline & DB RCT & R 25 mg (61) & 19.7 & 18.0 & \\
\hline & NCT01430442 & R 75 mg (86) & 31.4 & 27.9 & \\
\hline
\end{tabular}

Continued. 


\begin{tabular}{|c|c|c|c|c|c|}
\hline Author/year & Study details & $\begin{array}{l}\text { Intervention } \\
(\mathbf{N})\end{array}$ & $\begin{array}{l}\text { Percentage of } \\
\text { patients pain } \\
\text { free at } 2 \mathrm{hrs}\end{array}$ & $\begin{array}{l}\text { Percentage of } \\
\text { patients MBS- } \\
\text { free at } 2 \text { hrs }\end{array}$ & $\begin{array}{l}\text { Commonly } \\
\text { reported TEAE }\end{array}$ \\
\hline & & R 150 mg (85) & 32.9 & 25.9 & \\
\hline & & $\begin{array}{l}\text { R } 300 \mathrm{mg} \\
(111)\end{array}$ & 29.7 & 23.4 & \\
\hline & & R 600 mg (82) & 24.4 & 19.5 & \\
\hline & & Placebo (203) & 15.3 & 11.8 & \\
\hline \multirow{2}{*}{$\begin{array}{l}\text { Lipton et al, } \\
2019 .{ }^{36}\end{array}$} & \multirow{2}{*}{$\begin{array}{l}\text { Phase III } \\
\text { DB RCT } \\
\text { NCT03237845 }\end{array}$} & R 75 mg (537) & 19.6 & 37.6 & \multirow{2}{*}{$\begin{array}{l}\text { Nausea } \\
\text { UTI }\end{array}$} \\
\hline & & Placebo (534) & 12.0 & 25.2 & \\
\hline \multirow{2}{*}{$\begin{array}{l}\text { Croop et al, } \\
2019 .{ }^{37}\end{array}$} & \multirow{2}{*}{$\begin{array}{l}\text { Phase III } \\
\text { DB RCT } \\
\text { NCT03461757 }\end{array}$} & R 75 mg (669) & 21.2 & 35.1 & \multirow{2}{*}{$\begin{array}{l}\text { Nausea } \\
\text { UTI }\end{array}$} \\
\hline & & Placebo (682) & 10.9 & 26.8 & \\
\hline \multirow{2}{*}{$\begin{array}{l}\text { BHV3000- } \\
301 . .^{38}\end{array}$} & \multirow{2}{*}{$\begin{array}{l}\text { Phase III } \\
\text { DB RCT } \\
\text { NCT03235479 }\end{array}$} & R 75 mg (543) & 19.2 & 36.6 & \multirow[b]{2}{*}{ Not reported } \\
\hline & & Placebo (541) & 14.2 & 27.7 & \\
\hline \multicolumn{6}{|l|}{ Zavegepant } \\
\hline \multirow{4}{*}{$\begin{array}{l}\text { Croop et al, } \\
2021 .{ }^{39}\end{array}$} & \multirow{4}{*}{$\begin{array}{l}\text { Phase II/III } \\
\text { DB RCT } \\
\text { NCT03732638 }\end{array}$} & $\mathrm{Z} 5 \mathrm{mg}$ & 19.6 & 39 & \multirow{4}{*}{$\begin{array}{l}\text { Dysgeusia } \\
\text { Nasal discomfort }\end{array}$} \\
\hline & & $\mathrm{Z} 10 \mathrm{mg}$ & 22.5 & 41.9 & \\
\hline & & $\mathrm{Z} 20 \mathrm{mg}$ & 23.1 & 42.5 & \\
\hline & & Placebo & 15.5 & 33.7 & \\
\hline
\end{tabular}

Note: $\mathrm{N}=$ Number of patients in each group; MBS= Most bothersome symptom; TEAE= Treatment emergent adverse event among patients on investigational drug; DB RCT= Double-blinded randomized clinical trial; U= Ubrogepant; R= Rimegepant, Z=Zavegeapant; and *= percentage of patients photophobia-free.

Table 3: Summary of phase II/III clinical trials investigating second generation gepants for preventive therapy in episodic migraine.

\begin{tabular}{|c|c|c|c|c|c|}
\hline Author/year & Study details & $\begin{array}{l}\text { Intervention } \\
\text { groups }(\mathbf{N})\end{array}$ & $\begin{array}{l}\text { Change from } \\
\text { baseline in } \\
\text { mean } \\
\text { monthly } \\
\text { migraine days }\end{array}$ & $\begin{array}{l}\text { Patients with at } \\
\text { least } 50 \% \\
\text { reduction in mean } \\
\text { monthly days over } \\
\text { 3-months }\end{array}$ & $\begin{array}{l}\text { Commonly } \\
\text { reported } \\
\text { TEAEs }\end{array}$ \\
\hline \multicolumn{6}{|l|}{ Atogepant } \\
\hline $\begin{array}{l}\text { Goadsby et al, } \\
2020 .{ }^{40}\end{array}$ & $\begin{array}{l}\text { Phase IIb/III } \\
\text { DB RCT } \\
\text { NCT02848326 }\end{array}$ & $\begin{array}{l}\text { A } 10 \mathrm{mg} \text { OD (93) } \\
\text { A } 30 \mathrm{mg} \text { OD (183) } \\
\text { A } 60 \mathrm{mg} \text { OD (186) } \\
\text { A } 30 \mathrm{mg} \text { BID (86) } \\
\text { A } 60 \mathrm{mg} \text { BID (91) } \\
\text { Placebo (186) }\end{array}$ & $\begin{array}{l}-4.0 \\
-3.76 \\
-3.55 \\
-4.23 \\
-4.14 \\
-2.85\end{array}$ & $\begin{array}{l}57.6 \\
53.3 \\
52.0 \\
58.2 \\
62.1 \\
40.4\end{array}$ & $\begin{array}{l}\text { Nausea } \\
\text { Fatigue }\end{array}$ \\
\hline $\begin{array}{l}\text { Ailani et al, } \\
2021 .^{41}\end{array}$ & $\begin{array}{l}\text { Phase III } \\
\text { DB RCT } \\
\text { ADVANCE } \\
\text { NCT03777059 }\end{array}$ & $\begin{array}{l}\text { A } 10 \mathrm{mg} \text { OD (214) } \\
\text { A } 30 \mathrm{mg} \text { OD (223) } \\
\text { A } 60 \mathrm{mg} \text { OD (222) } \\
\text { Placebo OD (214) }\end{array}$ & $\begin{array}{l}-3.69 \\
-3.86 \\
-4.20 \\
-2.48\end{array}$ & $\begin{array}{l}55.6 \\
58.7 \\
60.8 \\
29.0\end{array}$ & $\begin{array}{l}\text { Constipation } \\
\text { Nausea } \\
\text { URTI }\end{array}$ \\
\hline \multicolumn{6}{|l|}{ Rimegepant } \\
\hline $\begin{array}{l}\text { Croop et al, } \\
2021.42\end{array}$ & $\begin{array}{l}\text { Phase II/III } \\
\text { DB RCT } \\
\text { NCT03732638 }\end{array}$ & $\begin{array}{l}\text { R } 75 \text { mg OD } \\
(348) \\
\text { Placebo (347) }\end{array}$ & $\begin{array}{l}-4.3 \\
-3.5\end{array}$ & $\begin{array}{l}49.1 \\
41.5\end{array}$ & $\begin{array}{l}\text { Nasopharyngitis } \\
\text { Nausea } \\
\text { UTI } \\
\text { URTI }\end{array}$ \\
\hline
\end{tabular}

Note: $\mathrm{N}=$ Number of patients in each group; TEAE $=$ Treatment emergent adverse event among patients on investigational drug; URTI= Upper respiratory tract infection; UTI= Urinary tract infection; A= Atogepant; and R= Rimegepant.

Table 4: Calcitonin Gene-Related Monoclonal antibodies (CGRP mAbs) used in migraine

\begin{tabular}{|lllll|}
\hline CGRP mAb & Erenumab & Galcanezumab & Fremanezumab & Eptinezumab \\
\hline Trade name & AIMOVIG & EMGALITY & AJOVY & VYEPTI \\
\hline Type & Human & Humanized & Humanized & Humanized \\
\hline Target & CGRP receptor & CGRP peptide & CGRP peptide & CGRP peptide \\
\hline Route & Subcutaneous (SC) & Subcutaneous (SC) & Subcutaneous (SC) & Intravenous (IV) \\
\hline
\end{tabular}




\begin{tabular}{|c|c|c|c|c|}
\hline CGRP mAb & Erenumab & Galcanezumab & Fremanezumab & Eptinezumab \\
\hline Dose & $\begin{array}{l}70 \mathrm{mg} \text { SC once a } \\
\text { month }\end{array}$ & $\begin{array}{l}120 / 240 \mathrm{mg} \mathrm{SC} \text { once a } \\
\text { month }\end{array}$ & $\begin{array}{l}675 \mathrm{mg} \mathrm{SC} \text { once a month } \\
\text { or every } 3 \text { months }\end{array}$ & $\begin{array}{l}100 \mathrm{mg} \text { IV every } \\
3 \text { months }\end{array}$ \\
\hline $\begin{array}{l}\text { Approved } \\
\text { Indication }\end{array}$ & Prevention of migraine & $\begin{array}{l}\text { Prevention of migraine } \\
\text { and cluster headaches }\end{array}$ & Prevention of migraine & $\begin{array}{l}\text { Prevention of } \\
\text { migraine }\end{array}$ \\
\hline $\begin{array}{l}\text { Included } \\
\text { RCTs }\end{array}$ & $\begin{array}{l}\text { NCT02630459 }^{43} \\
\text { ARISE }^{44} \\
\text { STRIVE }^{45}\end{array}$ & $\begin{array}{l}\text { NCT02163993 } \\
\text { EVOLVE- } 1^{47} \\
\text { EVOLVE-2 }^{48} \\
\text { CONQUER } \\
\text { NCT02959177 } \\
\text { No }\end{array}$ & $\begin{array}{l}\text { FOCUS } \\
\text { HALO }^{52,53}\end{array}$ & $\begin{array}{l}\text { PROMISE-1 } \\
\text { RELIEF }^{55}\end{array}$ \\
\hline
\end{tabular}

\section{CONCLUSION}

CGRP-based therapies (CGRP-RA and CGRP mAbs) have proven to be efficacious and well tolerated alternative for the treatment and prevention of migraine. Further studies are required to compare their efficacy with established treatments like triptans. Moreover, whether CGRP modulators can be employed for other headache syndromes needs to be explored.

Funding: No funding sources Conflict of interest: None declared

Ethical approval: Not required

\section{REFERENCES}

1. Burstein R, Noseda R, Borsook D. Migraine: multiple processes, complex pathophysiology. J Neurosci. 2015;35(17):6619-29.

2. Headache Classification Committee of the International Headache Society (IHS) The International Classification of Headache Disorders. Cephalalgia. 2018;38(1):1-211.

3. Goadsby PJ, Holland PR, Oliveira M, Hoffmann J, Schankin C, Akerman S. Pathophysiology of Migraine: A Disorder of Sensory Processing. Physiol Rev. 2017;97(2):553-622.

4. Harbi FG, Ateeq MA. Quality of life of migraine patients followed in neurology clinics in Riyadh, Saudi Arabia. J Family Community Med. 2020;27(1):37-45.

5. Steiner TJ, Stovner LJ, Jensen R, Uluduz D, Katsarava $\mathrm{Z}$, et al. Migraine remains second among the world's causes of disability, and first among young women: findings from GBD2019. J Headache Pain. 2020;21(1):137.

6. Hansen JM, Charles A. Differences in treatment response between migraine with aura and migraine without aura: lessons from clinical practice and RCTs. J Headache Pain. 2019;20(1):96.

7. Charles A. Migraine. N Engl J Med. 2017;377(6):55361.

8. Lipton RB, Fanning KM, Serrano D, Reed ML, Cady $\mathrm{R}$, Buse DC. Ineffective acute treatment of episodic migraine is associated with new-onset chronic migraine. Neurology. 2015;84(7):688-95.

9. Bigal ME, Serrano D, Buse D, Scher A, Stewart WF, Lipton RB. Acute migraine medications and evolution from episodic to chronic migraine: a longitudinal population-based study. Headache. 2008;48(8):115768.

10. Chiang CC, Schwedt TJ, Wang SJ, Dodick DW. Treatment of medication-overuse headache: A systematic review. Cephalalgia. 2016;36(4):371-86.

11. Bigal ME, Serrano D, Reed M, Lipton RB. Chronic migraine in the population: burden, diagnosis, and satisfaction with treatment. Neurology. 2008;71(8):559-66.

12. Alstadhaug KB, Ofte HK, Kristoffersen ES. Preventing and treating medication overuse headache. Pain Rep. 2017;2(4):612.

13. American Headache Society. The American Headache Society Position Statement On Integrating New Migraine Treatments Into Clinical Practice. Headache. 2019;59(1):1-18.

14. Blumenfeld AM, Bloudek LM, Becker WJ, Buse DC, Varon SF, Maglinte GA, et al. Patterns of use and reasons for discontinuation of prophylactic medications for episodic migraine and chronic migraine: results from the second international burden of migraine study (IBMS-II). Headache. 2013;53(4):644-55.

15. Edvinsson L, Haanes KA, Warfvinge K, Krause DN. CGRP as the target of new migraine therapies successful translation from bench to clinic. Nat Rev Neurol. 2018;14(6):338-50.

16. Hargreaves R, Olesen J. Calcitonin Gene-Related Peptide Modulators - The History and Renaissance of a New Migraine Drug Class. Headache. 2019;59(6):951-70.

17. Eftekhari S, Warfvinge K, Blixt FW, Edvinsson L. Differentiation of nerve fibers storing CGRP and CGRP receptors in the peripheral trigeminovascular system. J Pain. 2013;14(11):1289-303.

18. Eftekhari S, Salvatore CA, Calamari A, Kane SA, Tajti J, Edvinsson L. Differential distribution of calcitonin gene-related peptide and its receptor components in the human trigeminal ganglion. Neuroscience. 2010;169(2):683-96.

19. Miller S, Liu H, Warfvinge K, Shi L, Dovlatyan M, $\mathrm{Xu} \mathrm{C}$, Edvinsson L. Immunohistochemical localization of the calcitonin gene-related peptide binding site in the primate trigeminovascular system using functional antagonist antibodies. Neuroscience. 2016;328:165-83.

20. Williamson DJ, Hargreaves RJ, Hill RG, Shepheard SL. Sumatriptan inhibits neurogenic vasodilation of 
dural blood vessels in the anaesthetized rat--intravital microscope studies. Cephalalgia. 1997;17(4):525-31.

21. Lassen LH, Haderslev PA, Jacobsen VB, Iversen HK, Sperling B, Olesen J. CGRP may play a causative role in migraine. Cephalalgia. 2002;22(1):54-61.

22. Scott LJ. Ubrogepant: First Approval. Drugs. 2020;80(3):323-8.

23. Scott LJ. Rimegepant: First Approval. Drugs. 2020;80(7):741-6.

24. Deeks ED. Atogepant: First Approval. Drugs. 2021.

25. Markham A. Erenumab: First Global Approval. Drugs. 2018;78(11):1157-61.

26. Lamb YN. Galcanezumab: First Global Approval. Drugs. 2018 Nov;78(16):1769-75.

27. Hoy SM. Fremanezumab: First Global Approval. Drugs. 2018;78(17):1829-34.

28. Dhillon S. Eptinezumab: First Approval. Drugs. 2020;80(7):733-9.

29. Vries T, Villalón CM, MaassenVanDenBrink A. Pharmacological treatment of migraine: CGRP and 5HT beyond the triptans. Pharmacol Ther. 2020;211:107528.

30. Olesen J, Diener HC, Husstedt IW, Goadsby PJ, Hall $\mathrm{D}$, Meier U, et al. Calcitonin gene-related peptide receptor antagonist BIBN 4096 BS for the acute treatment of migraine. $\mathrm{N}$ Engl $\mathrm{J}$ Med. 2004;350(11):1104-10.

31. Edvinsson L, Linde $M$. New drugs in migraine treatment and prophylaxis: telcagepant and topiramate. Lancet. 2010;376(9741):645-55.

32. Voss T, Lipton RB, Dodick DW, Dupre N, Ge JY, Bachman R, et al. A phase IIb randomized, doubleblind, placebo-controlled trial of ubrogepant for the acute treatment of migraine. Cephalalgia. 2016;36(9):887-98.

33. Dodick DW, Lipton RB, Ailani J, Lu K, Finnegan M, Trugman JM, Szegedi A. Ubrogepant for the Treatment of Migraine. N Engl J Med. 2019;381(23):2230-41.

34. Lipton RB, Dodick DW, Ailani J, Lu K, Finnegan M, Szegedi A, Trugman JM. Effect of Ubrogepant vs Placebo on Pain and the Most Bothersome Associated Symptom in the Acute Treatment of Migraine: The ACHIEVE II Randomized Clinical Trial. JAMA. 2019;322(19):188798.

35. Marcus R, Goadsby PJ, Dodick D, Stock D, Manos G, Fischer TZ. BMS-927711 for the acute treatment of migraine: a double-blind, randomized, placebo controlled, dose-ranging trial. Cephalalgia. 2014;34(2):114-25.

36. Lipton RB, Croop R, Stock EG, Stock DA, Morris BA, Frost M, et al. Rimegepant, an Oral Calcitonin GeneRelated Peptide Receptor Antagonist, for Migraine. N Engl J Med. 2019;381(2):142-9.

37. Croop R, Goadsby PJ, Stock DA, Conway CM, Forshaw M, Stock EG, et al. Efficacy, safety, and tolerability of rimegepant orally disintegrating tablet for the acute treatment of migraine: a randomised, phase 3, double-blind, placebo-controlled trial Lancet. 2019;394(10200):737-45.
38. U.S National Library of Medical Clinical Trials Registry. Safety and Efficacy Study in Adult Subjects With Acute Migraines, 2021. Available at: https://www.clinicaltrials.gov/ct2/show/study/NCT03 235479. Accessed on 16 December 2021.

39. Croop R, Madonia J, Conway C, Thiry A, Forshaw M, Murphy A, et al. Intranasal Zavegepant is Effective and Well Tolerated for the Acute Treatment of Migraine: A Phase 2/3 Dose-Ranging Clinical trial (4976). Neurology. 2021;9(15):4976.

40. Goadsby PJ, Dodick DW, Ailani J, Trugman JM, Finnegan M, Lu K, et al. Safety, tolerability, and efficacy of orally administered atogepant for the prevention of episodic migraine in adults: a doubleblind, randomised phase $2 \mathrm{~b} / 3$ trial. Lancet Neurol. 2020;19(9):727-37.

41. Ailani J, Lipton RB, Goadsby PJ, Guo H, Miceli R, Severt L, et al. Atogepant for the Preventive Treatment of Migraine. N Engl J Med. 2021;385(8):695-706.

42. Croop R, Lipton RB, Kudrow D, Stock DA, Kamen L, Conway $\mathrm{CM}$, et al. Oral rimegepant for preventive treatment of migraine: a phase $2 / 3$, randomised, double-blind, placebo-controlled trial. Lancet. 2021;397(10268):51-60.

43. Sakai F, Takeshima T, Tatsuoka Y, Hirata K, Lenz R, Wang Y, et al. A Randomized Phase 2 Study of Erenumab for the Prevention of Episodic Migraine in Japanese Adults. Headache. 2019;59(10):1731-42.

44. Ashina M, Kudrow D, Reuter U, Dolezil D, Silberstein S, Tepper SJ, et al. Long-term tolerability and nonvascular safety of erenumab, a novel calcitonin gene-related peptide receptor antagonist for prevention of migraine: A pooled analysis of four placebo-controlled trials with long-term extensions. Cephalalgia. 2019;39(14):1798-808.

45. Goadsby PJ, Reuter U, Hallström Y, Broessner G, Bonner JH, Zhang F, et al. One-year sustained efficacy of erenumab in episodic migraine: Results of the STRIVE study. Neurology. 2020;95(5):469-79.

46. Skljarevski V, Oakes TM, Zhang Q, Ferguson MB, Martinez J, Camporeale A, et al. Effect of Different Doses of Galcanezumab vs Placebo for Episodic Migraine Prevention: A Randomized Clinical Trial. JAMA Neurol. 2018;75(2):187-93.

47. Stauffer VL, Dodick DW, Zhang Q, Carter JN, Ailani J, Conley RR. Evaluation of Galcanezumab for the Prevention of Episodic Migraine: The EVOLVE-1 Randomized Clinical Trial. JAMA Neurol. 2018;75(9):1080-8.

48. Skljarevski V, Matharu M, Millen BA, Ossipov MH, Kim BK, Yang JY. Efficacy and safety of galcanezumab for the prevention of episodic migraine: Results of the EVOLVE-2 Phase 3 randomized controlled clinical trial. Cephalalgia. 2018;38(8):1442-54.

49. Mulleners WM, Kim BK, Láinez MJA, Lanteri-Minet M, Pozo-Rosich P, Wang S, et al. Safety and efficacy of galcanezumab in patients for whom previous migraine preventive medication from two to four categories had failed (CONQUER): a multicentre, 
randomised, double-blind, placebo-controlled, phase $3 b$ trial. Lancet Neurol. 2020;19(10):814-25.

50. Shibata M, Nakamura T, Ozeki A, Ueda K, Nichols RM. Migraine-Specific Quality-of-Life Questionnaire (MSQ) Version 2.1 Score Improvement in Japanese Patients with Episodic Migraine by Galcanezumab Treatment: Japan Phase 2 Study. J Pain Res. 2020;13:3531-8.

51. Ferrari MD, Diener HC, Ning X, Galic M, Cohen JM, Yang R, et al. Fremanezumab versus placebo for migraine prevention in patients with documented failure to up to four migraine preventive medication classes (FOCUS): a randomised, double-blind, placebo-controlled, phase $3 \mathrm{~b}$ trial. Lancet. 2019;394(10203):1030-40.

52. Goadsby PJ, Silberstein SD, Yeung PP, Cohen JM, Ning X, Yang R, et al. Long-term safety, tolerability, and efficacy of fremanezumab in migraine: A randomized study. Neurology. 2020;95(18):2487-99.

53. Buse DC, Gandhi SK, Cohen JM, Campos V, Cloud $\mathrm{B}$, Yang $\mathrm{R}$, et al. Improvements across a range of patient-reported domains with fremanezumab treatment: results from a patient survey study. J Headache Pain. 2020;21(1):109.

54. Ashina M, Saper J, Cady R, Schaeffler BA, Biondi DM, Hirman J, et al. Eptinezumab in episodic migraine: A randomized, double-blind, placebocontrolled study (PROMISE-1). Cephalalgia. 2020;40(3):241-54.

55. Winner PK, McAllister P, Chakhava G, Ailani J, Ettrup A, Krog JM, et al. Effects of Intravenous Eptinezumab vs Placebo on Headache Pain and Most Bothersome Symptom When Initiated During a Migraine Attack: A Randomized Clinical Trial. JAMA. 2021;325(23):2348-56.

Cite this article as: Ahsan M, Mallick AK. Current status of calcitonin gene-related peptide-based therapies in migraine: a scoping review. Int J Basic Clin Pharmacol 2022;11:197-206. 